\title{
EVALUATION OF PROTOZOAN PARASITES CAUSING DIARRHOEA IN HIV POSITIVE PATIENTS
}

\author{
Uday Shankar1, Saral J. Ghosh ${ }^{2}$
}

${ }_{1}^{1}$ Post Graduate Student, Department of Microbiology, D. Y. Patil Medical College, Kolhapur, Maharashtra.

${ }^{2}$ Associate Professor, Department of Microbiology, D. Y. Patil Medical College, Kolhapur, Maharashtra.

\begin{tabular}{l} 
ABSTRACT \\
\hline BACKGROUND \\
Opportunistic parasitic infections are among the most serious infections in Human Immunodeficiency Virus (HIV) positive \\
patients and claim a number of lives every year. The present study was conducted to determine the prevalence of intestinal \\
parasites and to elucidate the association between intestinal opportunistic parasitic infection and CD4 (CD4+ T lymphocyte) counts \\
in HIV positive patients.
\end{tabular}

\section{METHODS}

The study was carried out at Department of Microbiology, on 50 HIV positive patients admitted to or attending the OPD of a tertiary healthcare centre in Kolhapur during the period from June 2013 to June 2015. Air dried smears from stool samples were stained by modified Acid fast stain, directly and after formol ether concentration technique for demonstrating oocysts of Cryptosporidium parvum, I. belli and C. cayetanensis.

\section{RESULTS}

Intestinal parasitic pathogens were detected in 54\% patients and the major pathogens included Cryptosporidium parvum (18\%), the most common followed by Entamoeba histolytica (14\%), Giardia lamblia (10\%), Ascaris lumbricoides (6\%) and $4 \%$ each of Isospora belli, Ancylostoma duodenale, Trichuris trichiura and Strongyloides stercoralis.

\section{CONCLUSION}

Intestinal parasitic infections caused diarrhoea in fifty four percent of patients, which was much more than the control group (16\%). Proportion of opportunistic pathogens in patients with CD4 count $<200$ cells $/ \mathrm{mm}^{3}$ was significantly higher (69\%) as compared to the patients having CD4 count $>200-499$ and $>500$ cells $/ \mathrm{mm}^{3}$.

\section{KEYWORDS}

Human Immunodeficiency Virus, Diarrhoea, Intestinal Parasites.

HOW TO CITE THIS ARTICLE: Shankar U, Ghosh SJ. Evaluation of protozoan parasites causing diarrhoea in HIV positive patients. J. Evolution Med. Dent. Sci. 2016;5(59):4064-4068, DOI: 10.14260/jemds/2016/931

\section{INTRODUCTION}

Gastrointestinal infections are very common in patients with HIV infection or AIDS. Diarrhoea is a common clinical presentation of these infections. Reports indicate that diarrhoea occurs in 30-60 percent of AIDS patients in developed countries and in about $90 \%$ percent of AIDS patients in developing countries.[1]

The aetiologic spectrum of enteric pathogens causing diarrhoea includes bacteria, parasites, fungi or enteric viruses. [2] In addition to microbes, other factors such as medication, immune deregulation, autonomic dysfunction and nutritional supplementation play substantial role in diarrhoea of HIV/AIDS patients. The presence of opportunistic parasites Cryptosporidium parvum, Cyclospora cayetanensis, Isospora belli, Toxoplasma gondii, Leishmania sp. and Microsporidia are documented in patient with AIDS. Other protozoan parasites like Entamoeba histolytica, which can cause invasive amoebiasis in HIV positive patients, Giardia lamblia and free living amoeba like Acanthamoeba and Balamuthia mandrillaris, which cause granulomatous

Financial or Other, Competing Interest: None.

Submission 02-05-2016, Peer Review 10-07-2016,

Acceptance 16-07-2016, Published 22-07-2016.

Corresponding Author:

Uday Shankar,

Department of Microbiology,

D. Y. Patil Medical College,

Kolhapur, Maharashtra.

E-mail: touday123@rediffmail.com

DOI: $10.14260 /$ jemds/2016/931 encephalitis also cause more disseminated and severe disease in HIV positive patients. Non-opportunistic parasites such as Trichuris trichiura, Ascaris lumbricoides, Strongyloides stercoralis and Ancylostoma duodenale are frequently encountered in developing countries, but not currently considered opportunistic in AIDS patients.[3] In immunocompromised or AIDS patients, the intestinal opportunistic parasites probably play a major role in causing chronic diarrhoea accompanied by weight loss and cause significant increase in morbidity and mortality. The incidence and prevalence of infection with a particular enteric parasite in HIV/AIDS patients is likely to depend on the endemicity of the particular parasite in the community.

C. parvum, I. belli, E. histolytica have been reported as the frequently identified organisms in HIV infected individuals with diarrhoea from India and other parts of the world. Besides this the nematode Strongyloides stercoralis a ubiquitous parasite in tropical and subtropical areas can cause diarrhoea and overwhelming infestation (Hyperinfection syndrome) in patients with a variety of immunosuppressive disorders including HIV/AIDS. A similar study on the prevalence of intestinal parasitic infestations in children was carried out in 2011 by Deodhar et al at Kolhapur, which showed a prevalence of different intestinal parasites at 45.5 percent. ${ }^{[4]}$

Parasites are ubiquitous in nature, but each geographical area has its unique ecology. Despite this predominance of certain aetiological agents in HIV/AIDS patients, it needs 
further research. The importance is clearly magnified for patients in tropical areas, which have high endemicity of parasitic infections.[5] The aim of the study was to compare the different protozoa causing diarrhoea in HIV positive patients and healthy control subjects and to study the relationship between the type of parasitic infection and CD4+ $\mathrm{T}$ cell count.

\section{METHODOLOGY}

A total of 50 HIV positive patients having diarrhoea admitted or attending the OPD of a tertiary healthcare centre in Kolhapur were taken up to determine the parasitic infections in the study group. Fifty, age and sex matched HIV negative individuals having diarrhoea were taken as controls.

HIV seropositive patients who had not received any antiprotozoal drugs in the last three weeks and having acute, chronic or intermittent diarrhoea were taken up for assessment in the present study. In the study, diarrhoea was defined as having three or more loose bowel movements within a 24-hour period. These cases were further divided into acute and chronic groups. Acute cases were defined as those in whom diarrhoea had lasted for up to 14 days, while those having diarrhoea for more than two weeks were defined as chronic.

Stool samples were examined for consistency, presence of mucus, pus, blood, adult worms and their segments and helminthic larvae. Microscopic examination of stool was done directly and after concentration by formol ether concentration technique.

Normal saline preparation of stool sample was examined for trophozoites of E. histolytica, G. lamblia, B. hominis, larvae of S. stercoralis, oocyst of I. belli and C. cayetanensis. Iodine preparation of stool sample was examined directly and after formol ether concentration for cysts of E. histolytica, G. lamblia and helminthic ova.

Air dried smears from stool samples were stained by modified Acid fast stain.[6] (Fixed in methanol for 5 minutes, stained with carbol fuchsin for 5 minutes, decolourised with acid alcohol $1 \%$ and counterstained with methylene blue for 1 minute) directly and after formol ether concentration technique for demonstrating oocysts of Cryptosporidium parvum, I. belli and C. cayetanensis.

\section{RESULTS}

During the study period, fifty HIV positive patients suffering from diarrhoea admitted to or attending a tertiary healthcare centre in Kolhapur were taken up to determine the parasitic infestation in the study group. Fifty age and sex matched HIV negative cases having diarrhoea were taken up as control.

Heterosexual route of transmission was observed in a majority of patients 46 cases (92\%), while intravenous drug abuse, blood transfusion and vertical transmission were seen in 0,0 and 4 cases respectively.

The age distribution of study group showed that maximum number of cases $(33 / 66 \%)$ were in the age group of $>25-50$ years followed by $10 / 20 \%$ cases in the age group of $12-25$ years, $5 / 10 \%$ were $>50$ years and $2 / 4 \%$ cases were in the $0-12$ years' age group as shown in Figure 1 . The control group also had maximum cases $23 / 46 \%$ in $>25-50$ years' age group followed by $18 / 36 \%$ cases in $>12-25$ years, $5 / 10 \%$ cases in $0-12$ years and $4 / 8 \%$ cases in $>50$ years' age group.
Out of the 50 HIV positive patients included 28 were males and 22 females, while the control group also had equal number of male and female cases.

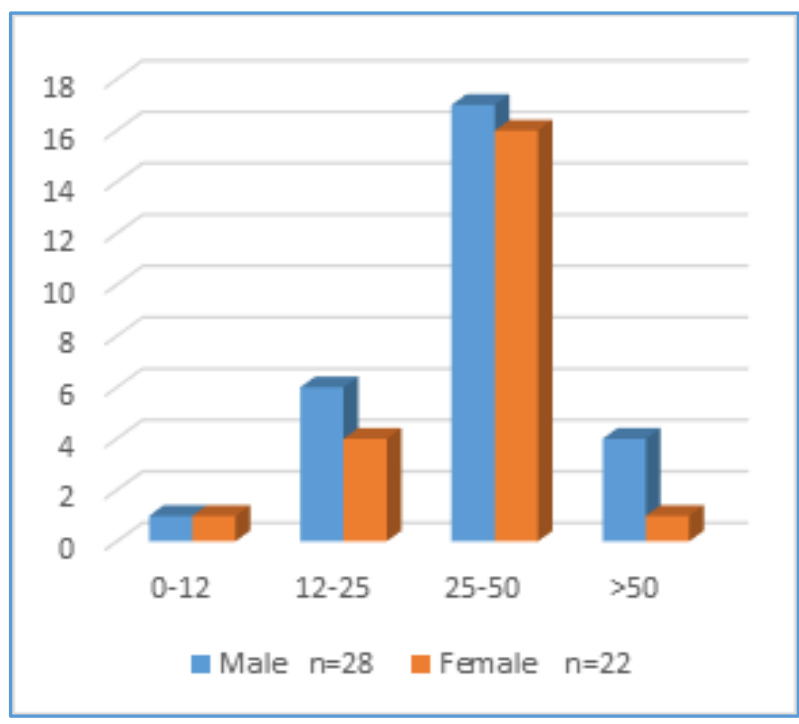
Fig. 1: Age and Sex Distribution of
HIV Positive Patients

The general prevalence of intestinal parasites in HIV infected and HIV non-infected were 54\% and $16 \%$ respectively. Among the 50 HIV infected patients, 31 (62\%) had chronic diarrhoea and 19 (38\%) of them had acute diarrhoea. Intestinal parasites were detected in 19 (38\%) patients with chronic diarrhoea and in $08(16 \%)$ of patients with acute diarrhoea as shown in Table 1.

\begin{tabular}{|c|c|c|c|c|c|c|}
\hline \multirow[b]{2}{*}{$\begin{array}{c}\text { Status of } \\
\text { Total } \\
\text { Diarrhoea }\end{array}$} & \multicolumn{3}{|c|}{ HIV + Cases } & \multicolumn{3}{|c|}{ HIV Non-Infected } \\
\hline & 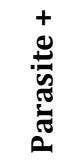 & 离 & $\sum_{\substack{\pi \\
0}}^{+}$ & 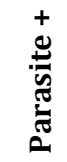 & 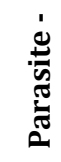 & 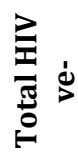 \\
\hline Acute & 08 & 11 & 19 & 05 & 33 & 38 \\
\hline Chronic & 19 & 12 & 31 & 03 & 09 & 12 \\
\hline Total & 27 & 23 & 50 & 08 & 42 & 50 \\
\hline \multicolumn{7}{|c|}{ Table 1} \\
\hline
\end{tabular}

All HIV positive patients enrolled in the study group suffered from diarrhoea. Thirty one cases (62\%) had a history of chronic diarrhoea lasting over two weeks, while 19 cases $(38 \%)$ had diarrhoea of less than 14 days' duration. All opportunistic coccidian parasites (i.e. C. parvum and I. belli) oocyst were detected only in HIV positive patients with chronic diarrhoea. Ascaris and hookworm species (Ancylostoma duodenale) were detected with almost equal frequency in the stool samples of HIV positive and HIV negative patients whereas majority of S. stercoralis, E. histolytica and G. lamblia were detected in diarrheic stool sample of HIV infected patients. Oocysts of C. parvum were seen in 9 cases $(18 \%)$ and cysts and/or trophozoites of G. lamblia were seen in five cases (10\%), cysts and/or trophozoites of E. histolytica in 7 cases $(14 \%)$ and two cases (4\%) each had S. stercoralis and I. belli cysts. Two cases (4\%) had ova of A. duodenale and T. trichiura and three cases had ova of A. lumbricoides.

In the control group only two cases (4\%) had cyst of G. lamblia and E. histolytica in the 12 to 25 years' age group and 
one case each of A. lumbricoides and A. duodenale in the 0-12 years' age group and one case each in the 12 to 25 years' age group. No parasitic infection could be detected in the other age groups.

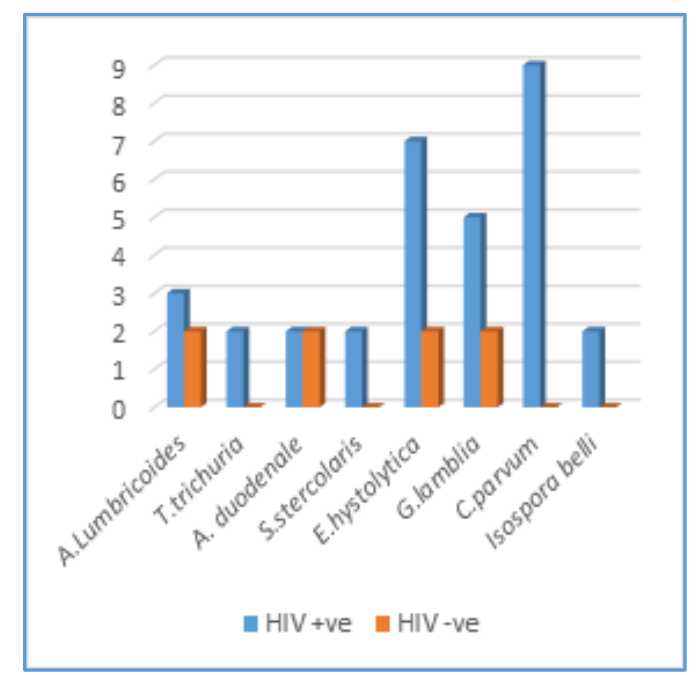

Fig. 2: Distribution of Enteric Parasites in HIV Positive and Negative Patients

A total of 100 stool samples (50 from HIV +ve and 50 from HIV -ve controls) were examined and a higher detection rate was observed after formol ether concentration than by direct iodine preparation. Qualitatively, all parasites which were detected by direct iodine staining were also detected by formol ether concentration, but with different rates of recovery. Detection of Ascaris lumbricoides was 5 (5\%) by formol ether method and $3(3 \%)$ by direct iodine method. Giardia cysts were found to be higher in formol ether method (7\%) than with direct iodine preparation (6\%), but no significant difference was observed. A. duodenale was found to be significantly more by formol ether method (4\%) than by direct iodine preparation. Cryptosporidium oocysts were found in eight patients after direct smear and in nine patients after formol ether concentration when stained with modified ZN method. No Cryptosporidium was identified in control (HIV negative) using either method.

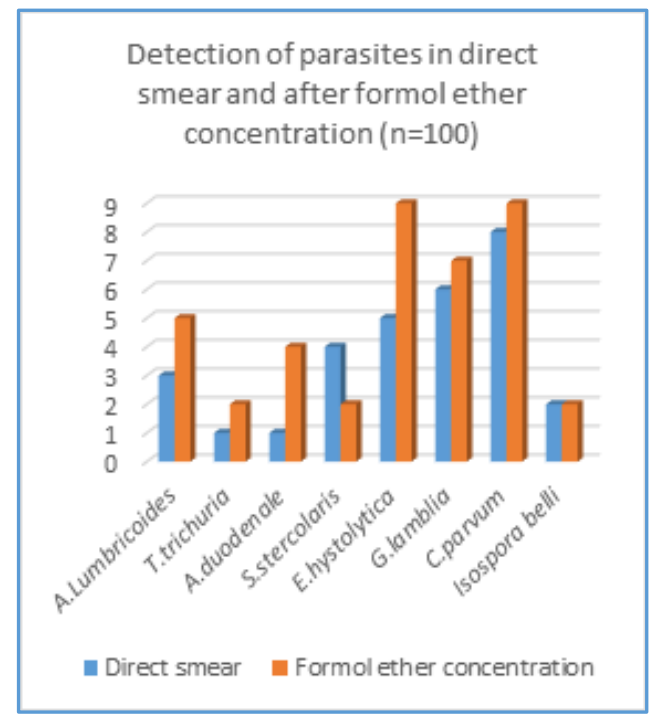

Fig. 3: Parasites Detected in Direct Smear and after Formol Ether Concentration
Ninety four percent of HIV +ve cases had CD4 counts below 500 cells $/ \mathrm{mm} 3$ of which $32 \%$ had CD4 count of $<200$ cells $/ \mathrm{mm} 3$ and $62 \%$ had CD4 count between 200 to 500 cells $/ \mathrm{mm} 3$ as shown in Figure 4 . Sixteen cases had CD4 count $<200$ cells/ mm3.

Eleven out of sixteen patients having CD 4 count $<200$ had parasitic infection detected on stool microscopic examination as shown in Fig. 4, out of which three had multiple parasitic infections. Seventeen of the thirty one cases with CD4 count between 200-500 cells $/ \mathrm{mm}^{3}$ had intestinal parasitic infection. Out of three patients with CD 4 count $>500$ one had parasitic infection on stool examination. Protozoa were more commonly encountered as compared to of helminthic infections.

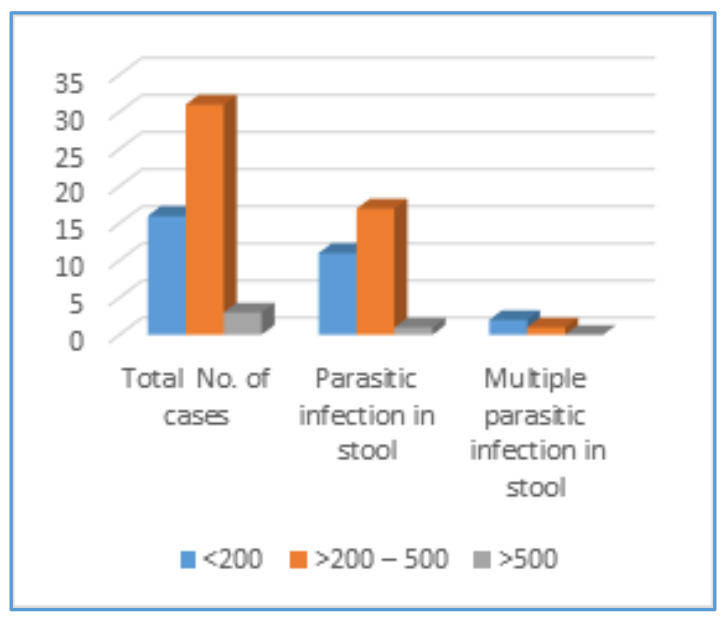

Fig. 4: Correlation of Parasitic Infection with CD4 Count in HIV Positive Cases

\section{DISCUSSION}

The number of immune-compromised host continues to increase due to an aggressive medical and surgical treatment for previously incurable illnesses and the emergence of HIV/AIDS worldwide. At the end of 2011, the adult prevalence in India was reported as $0.27 \%$. Number of PLHA (People Living with HIV/AIDS) were 20.8 lakh adults and 1.4 lakh children. Andhra Pradesh was the worst affected state followed by Maharashtra and Karnataka in terms of PLHA. However, as far as prevalence is concerned North East states such as Nagaland, Mizoram and Manipur are the worst affected.

In a compromised host not only is the risk of infection greater, the infection is also severe, rapidly progressive and occurs at unusual sites with atypical symptoms. All types of infection are associated with higher rates of morbidity and mortality in the immune compromised patients. The progressive destruction of the immune system by chronic HIV infection leading to progressive fall in level of CD4+ T cells $(<200)$ is responsible for the occurrence of infections by opportunistic micro-organisms including bacteria, viruses, fungi and parasites.

A total of twenty seven patients (54\%) out of fifty HIV positive patients in our study group had one or more parasitic infection on stool microscopic examination, which is comparable with the study conducted by Manish Kumar et al who reported that $50.36 \%$ patients had parasitic infestations in HIV positive patients having diarrhoea as shown in Table 2. 
All HIV positive patients enrolled in the study group suffered from diarrhoea. Thirty one cases (62\%) had a history of chronic diarrhoea lasting over two weeks, while 19 cases (38\%) had diarrhoea of less than 14 days' duration. Protozoa were more commonly encountered $(46 \%)$ as compared to $(16 \%)$ helminthic infections.
All opportunistic coccidian parasites (i.e. C. parvum and I. belli) oocyst were detected only in HIV positive patients with chronic diarrhoea. Ascaris and hookworm species (Ancylostoma duodenale) were detected with almost equal frequency in the stool samples of HIV positive and HIV negative patients, whereas majority of S. stercoralis, E. histolytica and G. lamblia were detected in diarrheic stool sample of HIV infected patients.[7]

\begin{tabular}{|c|c|c|c|c|c|c|}
\hline Study Series & Year & C. parvum & I. belli & A. duodenale & E. histolytica & G. lamblia \\
\hline $\begin{array}{c}\text { M K } \\
\text { Mathur et al[8] }\end{array}$ & 2013 & $135(24.8 \%)$ & $42(7.7 \%)$ & $34(6.25 \%)$ & $49(9.0 \%)$ & $21(6.33)$ \\
\hline $\begin{array}{c}\text { S Deorukhkar et } \\
\text { al[9] }\end{array}$ & 2011 & $32(9.64 \%)$ & $19(5.72 \%)$ & $29(8.7 \%)$ & $3(27.41)$ \\
\hline $\begin{array}{c}\text { K K Dwivedi } \\
\text { et al[10] }\end{array}$ & 2007 & $23(46 \%)$ & $2(4 \%)$ & $4(8 \%)$ & $8(16 \%)$ \\
\hline $\begin{array}{c}\text { S Assefa } \\
\text { et al[11] }\end{array}$ & 2009 & $43(20.1)$ & $26(12.2 \%)$ & $7(3.3 \%)$ & $53(24.8 \%)$ & $24(11.2 \%)$ \\
\hline Present study & 2015 & 9 (18\%) & $2(4 \%)$ & $2(4 \%)$ & $7(14 \%)$ & $5(10 \%)$ \\
\hline \multicolumn{7}{|c|}{ Table 2: Parasites Recovered from Diarrhoeal Stool Samples in Various Studies } \\
\hline
\end{tabular}

The presence of enteric pathogens is strongly associated with severe immunodeficiency, particularly with CD4+Tlymphocytes counts below 500 cells $/ \mathrm{mm}^{3}$. The rate of enteric infections was found to be higher in patients with CD4 cell counts below 200 cells $/ \mathrm{mm}^{3}$ as shown in Table 3 .

\begin{tabular}{|c|c|c|c|c|}
\hline $\begin{array}{c}\text { Study } \\
\text { Series }\end{array}$ & Year & $\begin{array}{c}\text { CD4< } \\
\mathbf{2 0 0}\end{array}$ & $\begin{array}{c}\text { CD4 200- } \\
\mathbf{5 0 0}\end{array}$ & $\begin{array}{c}\text { CD4 } \\
>500\end{array}$ \\
\hline $\begin{array}{c}\text { K K } \\
\text { Dwivedi } \\
\text { et al[10] }\end{array}$ & 2006 & $27(54 \%)$ & $9(18 \%)$ & $22(45 \%)$ \\
\hline $\begin{array}{c}\text { S Assefa } \\
\text { et al[11] }\end{array}$ & 2009 & $51(83 \%)$ & $55(53 \%)$ & $22(45 \%)$ \\
\hline $\begin{array}{c}\text { N Vyas } \\
\text { et al[4] }\end{array}$ & 2012 & $\begin{array}{c}118 \\
(72.8 \%)\end{array}$ & $\begin{array}{c}38 \\
(23.4 \%)\end{array}$ & $6(3.7 \%)$ \\
\hline $\begin{array}{c}\text { Present } \\
\text { study }\end{array}$ & 2015 & $\begin{array}{c}11 \\
(68.75 \%)\end{array}$ & $\begin{array}{c}17 \\
(54.8 \%)\end{array}$ & $1(33.3 \%)$ \\
\hline $\begin{array}{c}\text { Table 3: Distribution of Enteric Parasites according to CD4 } \\
\text { Count in HIV Infected Patients }\end{array}$ \\
\hline
\end{tabular}

The result of this study may reflect only a minimal estimate of the burden of diarrhoeal disease, because diarrhoeal episodes were counted only if they were present at the time of collection of the specimen. A decrease of enteric pathogens due to improvement of the immune functions and clinical improvement also results in clearance of the parasites.

Maximum numbers of cases in the study group were in 12-50 years' age group (43 in HIV positive and 41 in HIV negative). There were 28 males and 22 females in the HIV positive age group. According to the data available, most of the HIV/AIDS infections are in the age group of 15-49 years with heterosexual transmission being the predominant mode of HIV infection and distribution of males and females being $79 \%$ and $21 \%$ respectively. 12 Our study group also had maximum number of $\mathrm{HIV}(+)$ cases $(43 / 50)$ between $12-50$ years' age group and heterosexual transmission was the predominant mode of HIV infection and the number of HIV(+) males and females in the study group was twenty eight and twenty two respectively.

\section{CONCLUSION}

Intestinal parasitic infections caused diarrhoea in fifty four percent of patients, which was much more than the control group (16\%). Most of the patients with CD4 count $<200$ cells $/ \mathrm{mm}^{3}$ had intestinal infection with opportunistic parasites. The result of our study highlights the importance of evaluation of HIV infected individuals with diarrhoea for intestinal parasitic infections, which may help in better management of these patients. Aetiology of diarrhoea could not be determined in 46 percent of patients, suggesting a need for comprehensive aetiological studies covering bacterial, fungal and viral causes of diarrhoea among HIV infected patients in India.

\section{ACKNOWLEDGEMENT}

We thank all our colleagues in the department for assisting us in conducting this study.

\section{REFERENCES}

1. Kulkarni SV, Kairon R, Sane SS, et al. Opportunistic parasitic infections in HIV/AIDS patients presenting with diarrhoea by the level of immune suppression. Indian Journal of Medical Research 2009;130(1):63-6.

2. Mitra AK, Hernandez CD, Hernandez CA, et al. Management of diarrhoea in HIV infected patients. Int J STD AIDS 2001;12(10):630-9.

3. Goodgame RW. Understanding intestinal spore forming protozoa: cryptosporidia, microsporidia, isospora cyclospora. Ann Intern Med 1996;124(4):429-41.

4. Deodhar GA, Purohit V. Prevalence of parasitic infestations in children at Patil DY medical college, hospital and research Institute, Kolhapur. A J University 2011;1:86-9.

5. Vyas N, Pathan N, Aziz A. Enteric pathogens in HIVpositive patients with diarrhoea and their correlation with CD4+ T-lymphocyte counts. Trop Parasitol 2012;2(1):29-34.

6. Kehi KS, Cicirello H, Havens PL. Comparison of four different methods for detection of cryptosporidium species. Clin Microbiol 1995;33(2):416-8. 
7. Ramakrishnan K, Shenbagarathai R, Uma A, et al. Prevalence of intestinal parasite infection in HIV/AIDS patients with diarrhoea in Madurai, south India. Jpn J Infect Dis 2007;60(4):209-10.

8. Mathur MK, Verma AK, Makwana GE, et al. Study of opportunistic intestinal parasitic infections in human immune deficiency virus patients. Journal of Glob Infect Dis 2013;5(4):164-7.

9. Deorukhkar S, Katiyar R, Saini S, et al. The prevalence of intestinal parasitic infections in HIV infected patients in a rural tertiary care hospital of western Maharashtra (A 5-year study). Journal of Clinical and Diagnostic Research 2011;5(2):210-2.
10. Dwivedi KK, Prasad G, Saini S, et al. Enteric opportunistic parasites among HIV infected individuals: associated risk factors and immune status. Jpn J Infect Dis 2007;60(23):76-81.

11. Aseefa S, Erko B, Medhin G, et al. Intestinal parasitic infections in relation to HIV/AIDS status, diarrhoea and CD4+ T-cell count. BMC Infectious Diseases 2009;9:155.

12. Gupta K, Bala M, Deb M, et al. Prevalence of intestinal parasitic infection in HIV infected individuals and their relationship with immune status. Indian J Med Microbiol 2013;31(2):161-5. 